\title{
Acumulação de capacidades tecnológicas e performance técnico- econômica: diferenças inter-empresariais na indústria moveleira no Rio Grande do Sul
}

\author{
Fernando Ben*
}

\begin{abstract}
Resumo
Este artigo examina as implicações da acumulação de capacidades tecnológicas para diferenças entre empresas em termos de aprimoramento da performance técnico-econômica. Essas questões são examinadas por meio do estudo de caso comparativo em duas empresas da indústria moveleira no estado no Rio Grande Sul: D'Itália Moveis Industriais Ltda (1990-2000) e Pozza SA Industrial Moveleira (1963-2000). A métrica para examinar capacidades tecnológicas identifica tipos e níveis de capacidades para três funções: (i) processos e organizações da produção; (ii) produtos e (iii) equipamentos. 0 exame da performance técnico-econômica é realizado à base de 16 diferentes indicadores. Este estudo baseia-se em evidências empíricas de primeira-mão coletadas por meio de múltiplas técnicas durante extensivo trabalho de campo nas duas empresas. Embora as duas empresas tenham nascido e crescido no mesmo setor industrial e tenham operado durante grande parte de suas existências sob idênticas condições setoriais e macro-econômicas, foram encontradas diferenças significativas em termos do modo e velocidade de acumulação tecnológica. Grande parte dessas diferenças, por sua vez, refletiram-se nas diferenças entre as empresas em termos de aprimoramento de vários indicadores de performance técnico-econômica.
\end{abstract}

Palavras chave: Capacidade tecnológica; performance técnico-econômica; indústria moveleira.

\begin{abstract}
This paper examines the implications of technological capability accumulation for inter-firm differences in terms of techno-economic performance improvement. Such issues are examined on the basis of a comparative case study of two firms of the furniture industry in the state of Rio Grande do Sul (Southern Brazil): D'Itália Moveis Industriais Ltda (19902000) e Pozza SA Industrial Moveleira (1963-2000). The framework to examine technological capability identifies types and levels of capability for three functions: (i) process and production organization; (ii) products; (iii) equipment related activities. Techno-economic performance is examined here on the basis of 16 different indicators. This article draws on first-hand empirical framework collected through multiple data-gathering techniques during an extensive fieldwork. Although the two case-study firms have been born and grown under the same industrial sector and, during a great part of their existence they operated under identical sectoral and macro-economic conditions, the study found significant differences between these two firms in terms of the manner and speed of technological capability accumulation. The evidence suggests that a large part of such differences were reflected in the differences between the two firms in terms of techno-economic performance.
\end{abstract}

Key words: technological capability; techno-economic performance; furniture industry.

\footnotetext{
* Professor do Departamento de Economia e Contabilidade da Universidade de Caxias do Sul - . E-mail: fernandb@ terra.com.br. Endereço: Campus Universitário da Região dos Vinhedo, 3.200 / Bloco F. Alameda João Dal Sasso, 800. CEP: 95.700-000, Bento Gonçalves-RS.

Artigo recebido em novembro de 2004 e aceito para publicação em março de 2005.
} 


\section{Introdução}

Embora a teoria econômica convencional tenda a enxergar empresas como um conjunto homogêneo de agentes econômicos, desde os anos 1950s pesquisadores têm buscado explicações para diferenças entre empresas, que operam no mesmo setor industrial e sob condições macro-econômicas idênticas, em termos de acumulação tecnológica e performance técnico-econômica. Especificamente, o tema das implicações das capacidades da firma para aprimoramento de sua performance técnico-econômica está refletido em clássicos estudos gerados, principalmente, a partir da emergência da 'perspectiva baseada em recursos' (Penrose, 1959; Hollander, 1965; Rumelt, 1974). Desde então, vários pesquisadores têm investigado o papel das capacidades tecnológicas para explicar diferenças entre empresas e setores industriais em termos de aprimoramento de performance técnicoeconômica, tais como pesquisas à luz da 'teoria evolucionista' (Nelson \& Winter, 1982; Dosi, 1985; Pavitt, 1991) a da abordagem das 'capacidades dinâmicas' (Teece et al. 1990; Teece \& Pisano, 1994).

Estudos sobre essas questões em empresas que operam no contexto de economias em desenvolvimento começaram a aparecer em meados dos anos 1970 por meio de um grupo pioneiro de pesquisadores na América Latina. Tais estudos foram implementados sob Programa de Pesquisa em Ciência e Tecnologia (ECLA/IBD/IDRC/UNDP), vários deles sumariados em Katz (1987). A maioria dos estudos da Ásia fez parte do projeto de pesquisa Aquisição de Capacidade Tecnológica, do Banco Mundial, sumariados em Katz (1987). Porém, do início dos anos 1980 ao início dos 1990 estudos dessa natureza tornaram-se escassos. Essa ausência de estudos limitou a geração de novas explicações sobre essas questões em empresas de economias emergentes, particularmente no Brasil. Somente em meados dos anos 1990 novos estudos, com adequado nível de profundidade, detalhe e cobertura de longo prazo, emergiram na literatura internacional para explicar a relação entre os processos de aprendizagem e a acumulação de capacidades tecnológicas em empresas de economias emergentes (Hobday, 1995; Kim, 1997a/b; Dutrénit, 2000; Ariffin, 2000; Figueiredo, 2001, 2003).

Figueiredo (2001) desenvolve e aplica modelos analíticos para explicar como os processos de aprendizagem influenciam o modo e a velocidade de acumulação de capacidades tecnológicas e, por sua vez, as diferenças entre empresas em termos de aprimoramento de performance técnica em siderúrgicas no Brasil. Estudos recentes adaptaram tais modelos para aplicá-los a empresas das indústrias eletro-eletrônica na Malásia e de bens de capital (fornecedora de plantas e sistemas para a indústria de celulose e papel) no Brasil (Ariffin, 2000; Tacla \& Figueiredo, 2003). Porém, esses estudos não examinam as implicações da acumulação tecnológica para performance técnico-econômica.

Por outro lado, Castro \& Figueiredo (2005) examinam as implicações dos processos de aprendizagem para a acumulação tecnológica e, por sua vez, para o aprimoramento da performance técnico-econômica em uma unidade chave de uma siderúrgica - a aciaria - Brasil. Porém, ainda há escassez no Brasil de estudos comparativos (entre empresas) sobre essas questões. Por isso, este artigo examina as implicações da acumulação de capacidade tecnológica para diferenças entre duas empresas indústria moveleira no Rio Grande do Sul em termos de performance técnico-econômica.

Capacidade tecnológica é entendida aqui como a capacidade de introduzir mudanças técnicas incrementais em processos de fabricação do aço, desenvolvimento de produtos e melhoria de equipamentos. Em suma, são recursos incorporados no conhecimento tácito, experiência e habilidade dos indivíduos e nos sistemas organizacionais (Bell \& Pavitt, 1995). A maneira e a velocidade com que a empresa acumula as suas capacidades tecnológicas têm implicações para a maneira e a velocidade como seus indicadores de performance técnica e econômica são aprimorados ao longo do tempo (Dosi, 1985; Figueiredo, 2001, 2002).

Este artigo está organizado como segue. A Seção 2 apresenta a métrica para exame da acumulação de capacidades. O desenho e método do estudo subjacente a este artigo são apresentados na Seção 3. A Seção 4 apresenta evidências de acumulação de capacidade tecnológica nas empresas estudadas. As implicações da acumulação tecnológica para o aprimoramento de performance técnico-econômica nas duas empresas são examinadas na Seção 5. Por fim, A Seção 6 apresenta as conclusões do estudo e implicações para gestão. 


\section{Modelo para exame de capacidade tecnológicas, em nível de empresas, na indústria moveleira}

Capacidades tecnológicas são os recursos necessários para gerar e gerir aperfeiçoamentos e inovações em processos, serviços, produtos, equipamentos e engenharia de projeto. Esses recursos estão acumulados não apenas em sistemas físicos e nas mentes de técnicos, engenheiros, gerentes e operadores, mas, principalmente, no tecido organizacional e gerencial da empresa (Bell \& Pavitt, 1993, 1995; Figueiredo, 2001). Tal definição é análoga àquela utilizada em trabalhos anteriores (Lall, 1982, 1987 e 1992; Dahlman \& Westphal, 1982). Neste artigo, capacidades tecnológicas são estudadas à luz da métrica desenvolvida em Figueiredo (2001). Esta métrica foi adaptada e validada para aplicação empírica na indústria moveleira, conforme mostrado na Tabela 1.

Capacidades tecnológicas são medidas e descritas nesse trabalho pelo tipo e pelo nível de complexidade das atividades que a empresa é capaz de realizar ao longo do tempo, alinhando-se a outros estudos que utilizaram esse modelo de mensuração de capacidades tecnológicas (por exemplo, Ariffin, 2000; Figueiredo, 2001; Tacla e Figueiredo, 2003) 
Tabela 1. Métrica para exame de capacidades tecnológicas na indústria moveleira

\begin{tabular}{|c|c|c|c|c|}
\hline \multirow{2}{*}{$\begin{array}{c}\text { NÍVEIS DE } \\
\text { CAPACIDADE } \\
\text { TECNOLÓGICA }\end{array}$} & \multicolumn{4}{|c|}{ FUNÇÕES TECNOLÓGICAS E ATIVIDADES RELACIONADAS } \\
\hline & PROCESSO E ORGANIZAÇÃO DA PRODUÇÃO & PRODUTOS & & EQUIPAMENTOS \\
\hline \multicolumn{5}{|c|}{ CAPACIDADES DE ROTINA } \\
\hline BÁSICO & $\begin{array}{l}\text { Produção artesanal, com processos rudimentares. } \\
\text { Layout improvisado dos equipamentos. } \\
\text { Simples atividades de operacionalização da planta pro- } \\
\text { dutiva. }\end{array}$ & $\begin{array}{l}\text { Produtos rudimentares, atendendo a necessidades } \\
\text { básicas, e a requisitos funcionais. } \\
\text { Utilização de madeiras maciças e nativas. } \\
\text { Venda de móveis montados. }\end{array}$ & & $\begin{array}{l}\text { Equipamentos de produção manual (tupias, } \\
\text { furadeiras, lixadeiras de cinta, pistolas de } \\
\text { pintura) }\end{array}$ \\
\hline $\begin{array}{c}(2) \\
\text { RENOVADO }\end{array}$ & $\begin{array}{l}\text { Produção sob medida e produção sob encomenda. } \\
\text { Presença de PCP, com produção semi-seriada. } \\
\text { Layout funcional dos equipamentos de produção. } \\
\text { ISO } 9002 \text {. }\end{array}$ & $\begin{array}{l}\text { Diversificação de mix de produtos. ISO } 900 \\
\text { Produtos vendidos desmontados, com inclusão n } \\
\text { embalagens de esquemas de montagem. } \\
\text { Utilização de matérias primas alternativas. } \\
\text { Pequenos aprimoramentos em produtos. }\end{array}$ & & $\begin{array}{l}\text { Equipamentos semi-automáticos (furadeiras } \\
\text { múltiplas, cabines de pintura, esteiras de } \\
\text { transporte, alimentadores de máquinas). } \\
\text { Manutenção corretiva dos equipamentos. }\end{array}$ \\
\hline \multicolumn{5}{|c|}{ CAPACIDADES INOVADORAS } \\
\hline $\begin{array}{c}\text { (3) } \\
\text { EXTRA } \\
\text { BÁSICO }\end{array}$ & $\begin{array}{l}\text { Produção seriada. Otimização de lotes de produção. } \\
\text { Minimização de gargalos na produção. } \\
\text { Estudos para aprimoramento de processo, com equi- } \\
\text { pamentos convencionais e/ou automáticos. }\end{array}$ & \begin{tabular}{|l|} 
Aprimoramento intermitente em produtos. \\
Promoção de pequenas adaptações em modelos \\
de produtos já lançados pela empresa. \\
Criação de especificações próprias de produtos.
\end{tabular} & & $\begin{array}{l}\text { quipamentos automatizados (Ex. pintura por } \\
\text { stema ultravioleta). Manutenção preventiva } \\
\text { s equipamentos comuns e/ou automatizados, } \\
\text { m utilização de ferramentaria própria. }\end{array}$ \\
\hline $\begin{array}{l}\text { (4) } \\
\text { PRÉ- } \\
\text { INTERMEDIÁRIO }\end{array}$ & $\begin{array}{l}\text { Introdução de novas técnicas organizacionai } \\
\text { (p. ex. } 5 \mathrm{~S} \text {, Controle Estatístico da Produção (CEP). } \\
\text { Círculos de Controle da Qualidade (CCQ), Kanban, } \\
\text { MRP, TQC/TQM). } \\
\text { Existência de processos patenteados. }\end{array}$ & $\begin{array}{l}\text { Engenharia Reversa. Preocupação com a satisfa- } \\
\text { ção do consumidor. Início de atividades relacio- } \\
\text { nadas ao design. Aprimoramento constante em } \\
\text { produtos próprios. } \\
\text { Existência de produtos patenteados. }\end{array}$ & & $\begin{array}{l}\text { quipamento de usinagem (Fresas CNC). } \\
\text { lanutenção preditiva nos equipamentos con- } \\
\text { ncionais, semi-automáticos e automáticos } \\
\text { resas CNC). }\end{array}$ \\
\hline$\stackrel{\text { (5) }}{\text { INTERMEDIÁRIO }}$ & $\begin{array}{l}\text { Organização de Layout Celular. } \\
\text { Rotinização das inovações organizacional (p. ex. } 5 \mathrm{~S} \text {, } \\
\text { Controle Estatístico da Produção (CEP). Círculos de } \\
\text { Controle da Qualidade (CCQ), Kanban, MRP, } \\
\text { TQC/TQM). }\end{array}$ & $\begin{array}{l}\text { Desenho e desenvolvimento assistido de novos } \\
\text { produtos. Rotinização do design como diferencial } \\
\text { competitivo. Diversificação de produtos patente- } \\
\text { ados. }\end{array}$ & & $\begin{array}{l}\text { aplantação de robôs, linhas transfer, } \\
\text { ogramação desses equipamentos pelos fun- } \\
\text { onários da empresa, com assistência externa. }\end{array}$ \\
\hline $\begin{array}{l}\text { (6) } \\
\text { INTERMEDIÁRIO } \\
\text { SUPERIOR } \\
\end{array}$ & $\begin{array}{l}\text { Linha dedicada, com linearidade na disposição de má- } \\
\text { quinas e produtos fabricados. Introdução Linhas Trans- } \\
\text { fer, Sistema Flexível de Manufatura (FMS) }\end{array}$ & $\begin{array}{l}\text { Emprego da Engenharia de Produtos no desen- } \\
\text { volvimento de protótipos, assistido pelo cliente. }\end{array}$ & & $\begin{array}{l}\text { ogramação de robôs sem assistência externa. } \\
\text { quipamentos para Sistema Flexível de Manu- } \\
\text { tura (FMS). }\end{array}$ \\
\hline $\begin{array}{c}(7) \\
\text { AVANÇADO }\end{array}$ & $\begin{array}{l}\text { Desenvolvimento de novos processos de produção, } \\
\text { com suporte em engenharia e P\&D. }\end{array}$ & $\begin{array}{l}\text { Desenvolvimento de produtos originais, com base } \\
\text { em engenharia e P\&D. }\end{array}$ & & $\begin{array}{l}\text { esenvolvimento de equipamentos em parceria } \\
\text { m fabricantes, através de P\&D. }\end{array}$ \\
\hline
\end{tabular}




\section{Desenho e método de estudo}

O estudo subjacente a este estudo foi estruturado para examinar as seguintes questões: (i) a dinâmica de acúmulo de capacidades tecnológicas nas duas empresas de móveis desde a sua criação até 2000; (ii) as implicações da acumulação de capacidades para a performance técnico-econômica. Para examinar estas questões com adequado nível de detalhe e profundidade, foi necessária a coleta de evidências primárias, qualitativas e quantitativas, sobre as atividades tecnológicas e os diversos indicadores de performance técnicoeconômica. Essas evidências foram obtidas a partir de várias fontes: entrevistas com gerentes, engenheiros e técnicos, pesquisas a documentos (relatórios, padrões, dados históricos etc.) e observações diretas. Utilizou-se o método de estudo de caso comparativo (Yin, 2001) e as duas empresas foram selecionadas de maneira intencional (Patton, 1990). Essa estratégia permitiu o exame de questões ainda não observadas na literatura com adequado nível de profundidade e de detalhe. Logo, este estudo pretende contribuir para o aprofundamento do entendimento da relação entre as questões centrais apresentadas;; ou seja, pretende-se aqui fazer uma generalização analítica. A adaptação da estrutura na Tabela 1 foi feita baseada em entrevistas com especialistas da indústria moveleira.

\section{Acumulação de capacidades tecnológicas nas empresas estudadas}

\subsection{Capacidades para atividades de processos e organização da produção}

Apresentamos aqui uma breve comparação entre D'Itália e na Pozza em termos de acumulação de capacidades para atividades de processo e organização da produção. Essa análise é realizada a partir das evidências coletadas nas empresas. A trajetória de acumulação de capacidades tecnológicas das empresas estudadas na função processo e organização da produção, com base na Tabela 1, é apresentada na Figura 1.

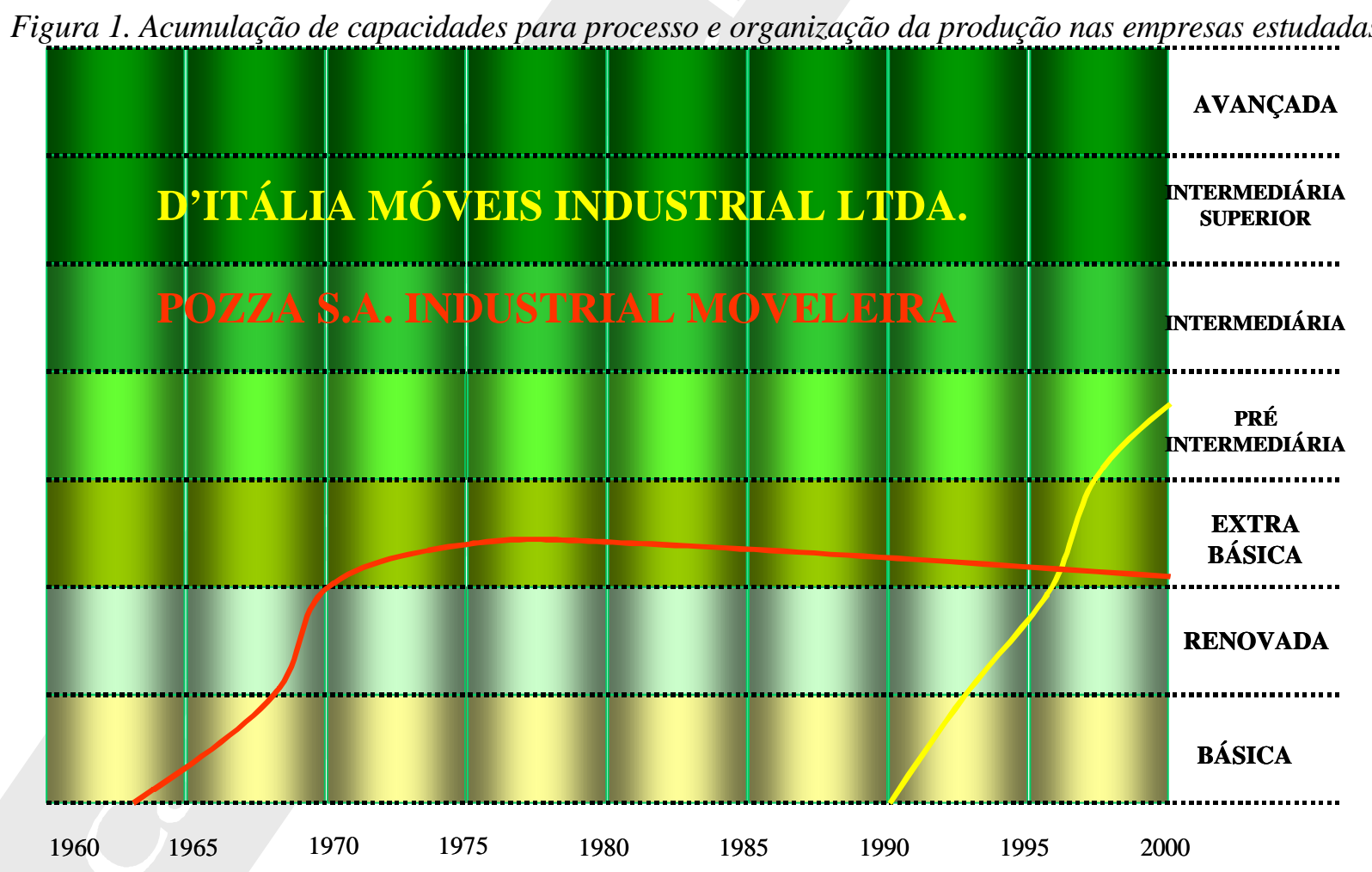

Fonte: Derivado do estudo 
A Figura 1 sugere que a D'Itália apresentou uma trajetória ascendente de acumulação de capacidades tecnológicas para esta função desde o início das atividades até 2000, tendo chegado até o Nível 4 (pré-intermediário) desta função. Enquanto isso, apesar de ter iniciado suas atividades quase trinta anos antes do que a D'Itália, a empresa Pozza, até 1970 acumulou capacidades tecnológicas na função processo e organização da produção a uma taxa semelhante à da D'Itália em seus primeiros anos de operação. Um crescimento mais lento foi encontrado durante a década de 1970. Após este período, a Pozza apresentou uma paralisação na acumulação de capacidades tecnológicas na função processo e organização da produção, tendo permanecido por muitos anos no mesmo nível. Assim, a Pozza atingiu o Nível 3 desta função tecnológica. Uma visualização mais detalhada do tempo que as empresas permaneceram em cada nível da Tabela 1 pode ser realizada através do Figura 2.

Figura 2. Tempo (em número de anos) de permanência em níveis específicos de capacidades para processos e organização da produção

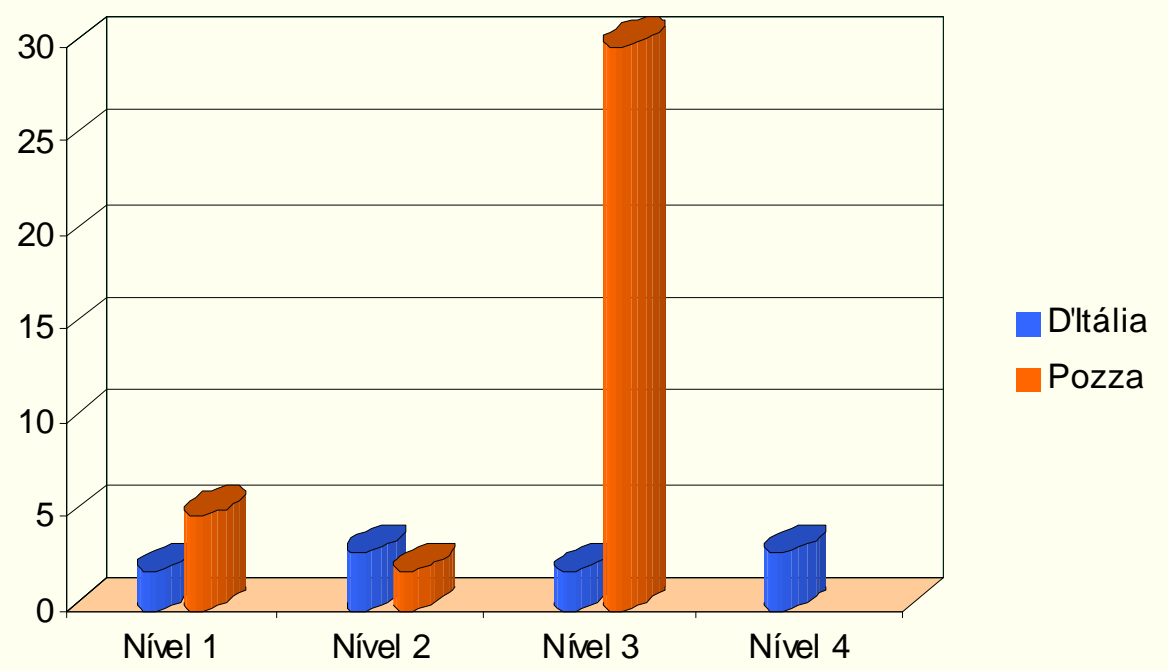

Pela observação da Figura 2, constata-se que a empresa D'Itália, além de ter evoluído de um nível para outro em um espaço de tempo menor do que a Pozza, apresenta-se atualmente em um nível de acumulação de capacidades tecnológicas superior ao apresentado pela Pozza em processo e organização da produção. Em contrapartida, constata-se que a empresa Pozza efetuou a transição do Nível 1 para o Nível 3 a uma velocidade semelhante à da D'Itália. Entretanto, a Pozza permaneceu, até 2000, por 30 anos no Nível 3 desta função. Este fato sugere ausência e/ou paralização de ações inovadoras por parte da Pozza.

A D'Itália acumulou suas capacidades mais rapidamente do que a Pozza. Na D'Itália, foram criados procedimentos para que as informações não ficassem somente na mente dos indivíduos, mas que fossem compartilhadas por todos. Além disso, os aspectos organizacionais e gerenciais igualmente contribuem para tanto. Por exemplo, em meados dos anos 1990 foi criado o encontro matinal para avaliar as metas, discutir os problemas e sugerir modificações. Em contrapartida, a Pozza não conseguiu acumular suas capacidades tecnológicas com a mesma velocidade em virtude de as informações não estarem codificadas e compartilhadas por todos os membros da organização.

Outro fator limitante ao desenvolvimento foi a paralisação da acumulação das capacidades tecnológicas, na função processo e organização da produção, por parte da Pozza, desde meados dos anos 1970 até 2000. Em função desta paralisação, não foi constatada neste período a utilização de novas formas de organização da produção. Dessa maneira, a Pozza elaborou seus produtos, durante todo esse período, utilizando sempre os mesmos procedimentos. Esse aspecto está alinhado aos estudos de Dosi (1998), onde o processo de evolução tecnológica em cada empresa é processo cumulativo. Assim, o que a empresa pode esperar fazer no futuro é definido estreitamente pelo que foi capaz de fazer no passado. Dessa maneira, em função de a Pozza ter paralisado as a- 
tividades de acumulação de capacidades tecnológicas nesta função durante um longo período, isso sugere reflexos no desempenho da empresa em períodos seguintes.

\subsection{Capacidades para atividades de produtos}

A Figura 3 ilustra a acumulação de capacidades tecnológicas para atividades de produtos nas duas empresas estudadas.

Figura 3. Acumulação de capacidades para atividades de produtos nas empresas estudadas

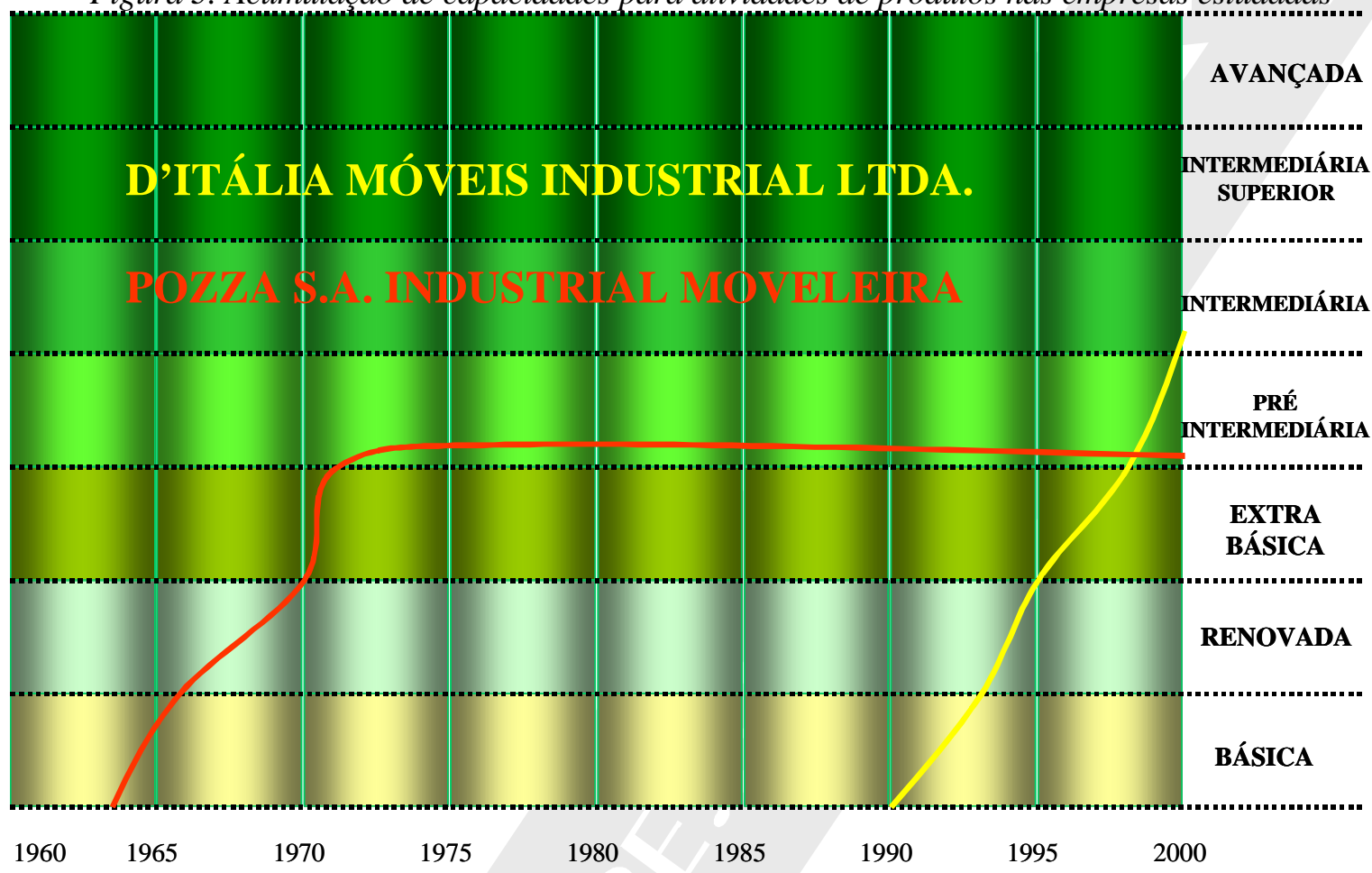

Fonte: Elaboração própria do autor

Pela Figura 3, observa-se que D'Itália apresentou uma evolução constante nessa função tecnológica, chegando ao Nível 5 em produtos. No ano de 2000, a D'Itália apresentou um nível mais elevado do que a Pozza, apesar de ser muito mais jovem do que esta. Em contrapartida, a Pozza acumulou capacidades tecnológicas na função produtos com uma trajetória crescente até 1970. Após este período, a Pozza apresentou uma paralisação na acumulação de capacidades tecnológicas na função produtos, tendo permanecido por muitos anos no Nível 4 desta função. A Figura 4 apresenta o tempo de permanência das empresas em cada nível da Tabela 1, referente à função produtos. 
Figura 4. Tempo (em número de anos) de permanência em níveis especificos de capacidades para atividades de produtos

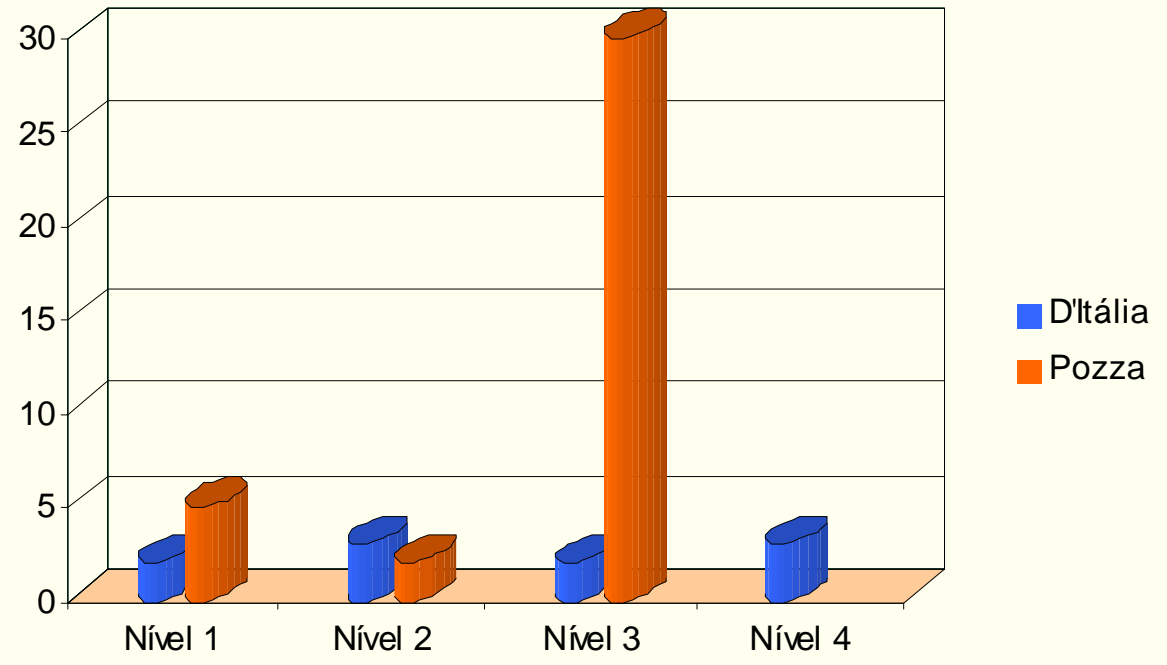

Observa-se um tempo de permanência semelhante em cada nível entre a D’Itália e Pozza até o Nível 3 desta função. O diferencial entre as empresas está nos Níveis 4 e 5 . Com relação ao Nível 4, enquanto a D'Itália demorou apenas dois anos para realizar a transição deste nível para o Nível 5, a Pozza permaneceu no mesmo Nível 4 durante 29 anos até 2000. Com isso, as inovações ocorridas durante este tempo não foram acompanhadas pela Pozza, fator este que apresentou consequiências marcantes na performance da empresa.

\subsection{Capacidades para atividades de equipamentos}

A Figura 5 a seguir ilustra a acumulação de capacidades para atividades relacionadas a equipamentos nas duas empresas estudadas.

Tabela 5 Acumulação de capacidades para atividades de produtos nas empresas estudadas

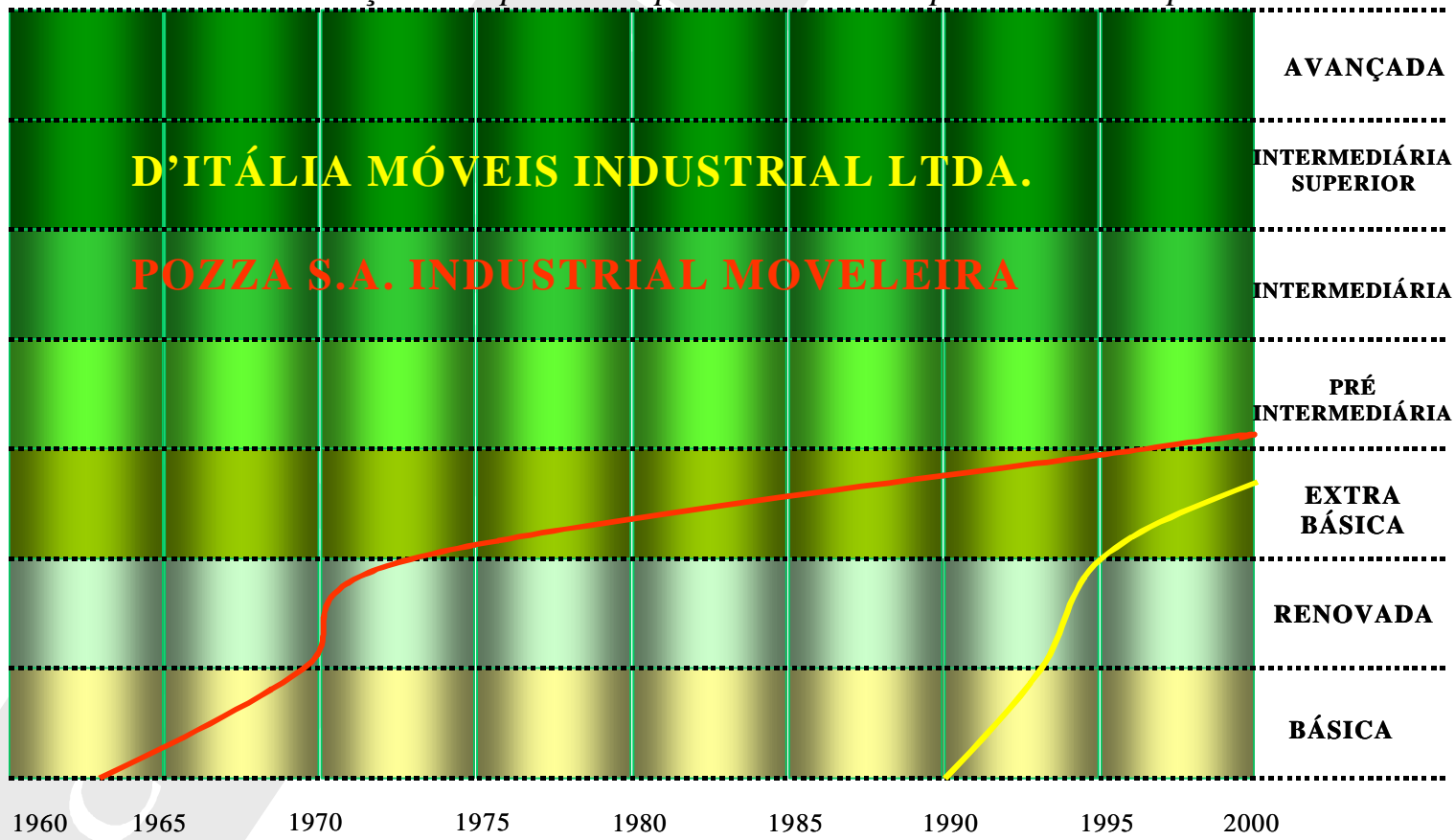

Fonte: Derivado do estudo 
A D'Itália apresentou índices constantes de crescimento em equipamentos, tendo chegado até o Nível 3 nesta função. Por sua vez, a empresa Pozza apresentou trajetória crescente na acumulação de capacidades tecnológicas em equipamentos até 1973. Entretanto, após este período, observa-se uma ausência de atividades inovadoras nesta função. A Pozza somente atingiu o Nível 4 em equipamentos no ano de 1997, com a chegada da fresa CNC. Com isso, a Pozza apresenta-se em um nível mais elevado do que a D'Itália nessa função, tendo chegado ao Nível 4. A Figura 6 descreve o tempo de permanência da D’Itália e da Pozza em cada nível da Tabela 1, referente à função equipamentos.

Figura 6. Tempo (em número de anos) de permanência em níveis específicos de capacidades para atividades de equipamentos

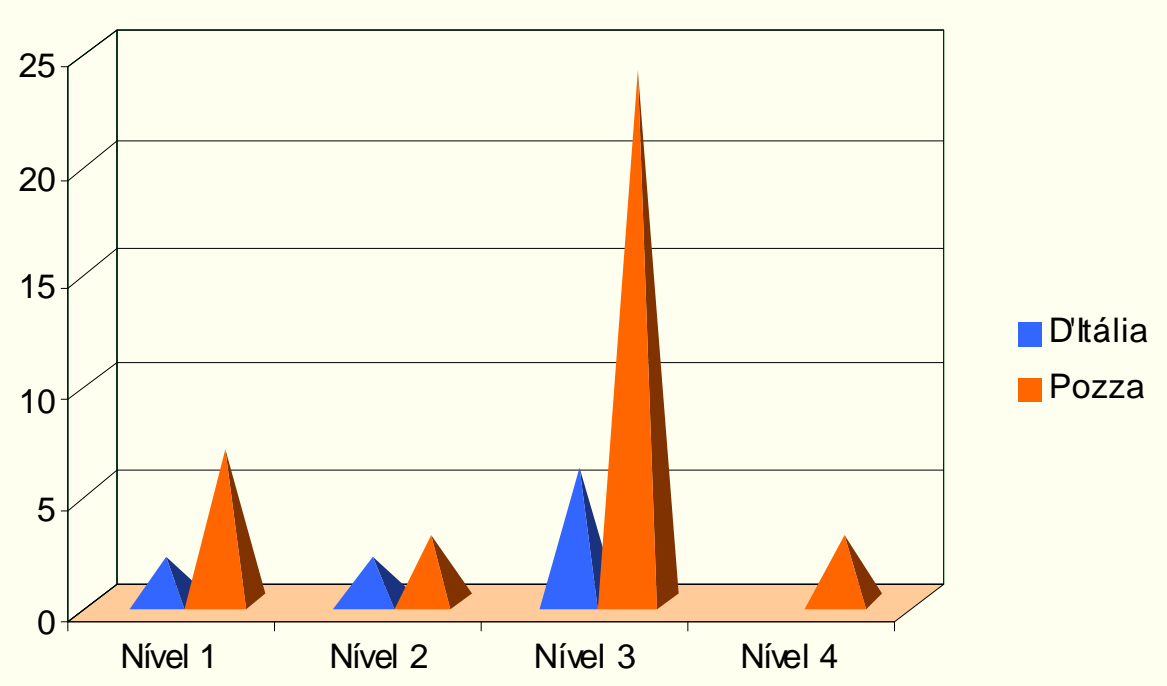

A Pozza, apesar de apresentar em todos os níveis um tempo maior para superar cada fase do que a empresa D’Itália, apresentava-se, em 2000, em um nível superior a esta. Além disso, a Pozza alcançou o Nível 4 de capacidades tecnológicas na função equipamentos. De outro lado, a D'Itália alcançou o Nível 3 em equipamentos. Contudo, ressalta-se que a Pozza necessitou de 24 anos para efetuar a transição do Nível 3 para o Nível 4.

Equipamentos é a única função tecnológica em que a Pozza acumulou um nível tecnológico mais elevado do que a D'Itália. Entretanto, evidências apontam que é insuficiente a empresa acumular capacidades tecnológicas somente em uma função, se não acumular nas demais funções também. A acumulação de capacidades tecnológicas deve ocorrer de maneira compreensiva, ou seja, ocorrer com a mesma velocidade em todas as funções tecnológicas da empresa. Segundo Figueiredo (2002), a acumulação de capacidades tecnológicas precisa acontecer de forma interdependente, pois uma função depende da outra. Estes estudos ainda sugeriram que o foco nas práticas organizacionais (p. ex. "benchmarking") pode ser até mesmo mais importante que as tecnologias microeletrônicas para empresas em contextos em industrialização. Contudo, verificou-se que a Pozza apresentou preocupações apenas em crescimento físico, com a aquisição de mais equipamentos para sua planta fabril. Em contrapartida, não foram verificados os mesmos esforços para processos e organização da produção e para produtos. Em resumo, para as funções analisadas, a D’Itália sempre apresentou trajetórias de acumulação que evoluíram consideravelmente mais rápido que as da Pozza. Além disso, nas três funções tecnológicas, a Pozza permaneceu um longo período sem apresentar atividades inovadoras.

\subsection{Síntese da acumulação de capacidades tecnológicas nas empresas estudadas}

À luz das evidências coletadas nas empresas, serão apresentados os níveis de acumulação de capacidades tecnológicas da empresas estudadas para as três funções tecnológicas apresentadas. De maneira geral, pode ser observado que a D'Itália acumulou capacidades muito mais rapidamente que a Pozza. Mas que, para a função equipamentos, apesar de ter atravessado um longo período com escassez de atividades inovadoras, a Pozza acumulou níveis mais elevados de capacidades que a D'Itália, conforme sintetizado na Tabela 2. 
Tabela 2. Número de anos (n) de permanência nos níveis de capacidade tecnológica pela D'Itália (1990 a 2000) e pela Pozza (1963 a 2000)

\begin{tabular}{|c|c|c|c|c|c|c|}
\hline \multirow{2}{*}{$\begin{array}{l}\text { Níveis de } \\
\text { capacidade } \\
\text { tecnológica }\end{array}$} & \multicolumn{2}{|c|}{$\begin{array}{l}\text { Processo e organização da } \\
\text { produção }\end{array}$} & \multicolumn{2}{|c|}{ Produtos } & \multicolumn{2}{|c|}{ Equipamentos } \\
\hline & D'Itália & Pozza & D’Itália & Pozza & D'Itália & Pozza \\
\hline $\begin{array}{l}\text { (1) } \\
\text { Básico }\end{array}$ & 2 & 5 & 2 & 3 & 2 & 7 \\
\hline $\begin{array}{l}\text { (2) } \\
\text { Renovado }\end{array}$ & 3 & 2 & 2 & 4 & 2 & 3 \\
\hline $\begin{array}{l}\text { (3) } \\
\text { Extra-Básico }\end{array}$ & 2 & 30 & 3 & 1 & 6 & 24 \\
\hline $\begin{array}{l}\text { (4) } \\
\text { Pré- } \\
\text { Intermediário }\end{array}$ & 3 & - & 2 & 29 & - & 3 \\
\hline $\begin{array}{l}\text { (5) } \\
\text { Intermediário }\end{array}$ & - & - & 1 & - & - & - \\
\hline
\end{tabular}

Fonte: Derivado do estudo

O tempo de permanência da D'Itália e da Pozza em cada nível da Tabela 1, para as três funções tecnológicas analisadas, é apresentado na Tabela 2. De maneira geral, verifica-se que a empresa D'Itália, apesar de ser mais jovem do que a Pozza, permaneceu menor tempo em cada Nível da Tabela 1. Assim, em 2000 a D'Itália apresenta-se no Nível 4 desta função, enquanto a D'Itália permaneceu durante 30 anos no Nível 3. Nesta seção, verifica-se que novamente a D'Itália permaneceu menor tempo em cada Nível da Tabela 1. Atualmente, a D'Itália encontra-se no Nível 5 desta tabela, enquanto a Pozza está a 29 anos no Nível 4. Finalmente, na Seção 4.2 foram resumidos os aspectos referentes à função equipamentos. Nesta seção, constata-se que a Pozza, apesar de ter permanecido 24 anos no Nível 3 da Tabela 1, no ano de 2000 encontrava-se em um nível mais elevado do que a D'Itália.

\section{Implicações das capacidades tecnológicas para 0 aprimoramento de indicadores de performance técni- co-econômica nas empresas estudadas}

Esta seção examina as implicações da acumulação de capacidades tecnológicas para as diferenças entre D’Itália Móveis Industrial Ltda. (1990 a 2000) e Pozza S.A. Industrial Moveleira (1963 a 2000) de performance técnico-econômica. A Seção 5.1 examina as implicações da acumulação tecnológica para o aprimoramento da performance técnica. A Seção 5.2 examina diferenças entre as suas empresas em termos de performance econômico-financeira.

\subsection{Aprimoramento de indicadores de performance técnica}

O aprimoramento da performance técnica é examinado aqui à base de dez indicadores organizados em quatro grupos conforme disposto na Tabela 3. Cada grupo de indicadores é examinado nas quatro sub-seções (5.1.1 a 5.1.4). 
Tabela 3. Indicadores de performance técnica

\begin{tabular}{ll}
\hline Indicador & Unidade de medida \\
\hline Grupo 1. Indicadores de custo de produção & \\
\hline (i) Consumo de energia & $\mathrm{Kw} / \mathrm{m}^{2}$ \\
\hline (ii) Produtividade do trabalho & Número de produtos/hora homem \\
\hline (iii) Taxa de utilização da capacidade instalada & $\%$ \\
\hline Grupo 2. Indicadores de qualidade da produção & $\%$ \\
\hline (iv) Îndice de peças refugadas & $\%$ \\
\hline (v) Taxa de reclamação de clientes & $\%$ \\
\hline Grupo 3. Indicador de velocidade da produção & \\
\hline (vi) Lead-time & Número de dias \\
\hline (vii) Tempo de set-up & Minutos/ano \\
\hline Grupo 4. Indicadores mercadológicos & \\
\hline (viii) Market-share & $\%$ \\
\hline (ix) Exportação & $\%$ \\
\hline (x) Número de patentes & Unidades \\
\hline
\end{tabular}

Fonte: Elaboração própria dos autores.

\subsubsection{Indicadores do Grupo 1}

Conforme apresentado na Tabela 3, o Grupo 1 é constituído por indicadores que descrevem a performance da empresa referente ao custo de produção. Esses indicadores são o consumo de energia, a produtividade do trabalho e a taxa de utilização da capacidade. O aprimoramento desses indicadores permite uma melhor competitividade da empresa no nível de custos. Assim, constata-se que no período de 1990 a 2000 a D'Itália apresentou uma significativa melhoria na performance operacional, principalmente nos quatro últimos anos do período (1997 a 2000).

Consumo de energia. A D'Itália apresentou o indicador consumo de energia com uma trajetória de crescimento até o ano de 1996. Somente a partir de 1997 esse indicador passou a apresentar melhoria em sua performance. Nesse mesmo período, a D'Itália passou a apresentar atividades de aprimoramento no processo produtivo, como a introdução dos lotes diários de produção. Tais atividades foram fundamentais para o aproveitamento da matéria prima processada e para a otimização do processo produtivo, pontos críticos para o indicador consumo de energia. Aliadas a estas atividades, outras como a utilização de equipamentos automatizados no processo produtivo e as melhorias no layout de produção também contribuíram para a melhoria desse indicador. A utilização de novas técnicas organizacionais (capacidade de Nível 4 em processo e organização da produção), como a introdução dos $5 \mathrm{~S}$, desencadeou novo processo de otimização da planta produtiva da D'Itália. Com a acumulação dessas capacidades, o consumo de energia na D'Itália que era de 0,57 Kw/m² em 1996 foi reduzido para $0,40 \mathrm{Kw} / \mathrm{m}^{2}$ em 1998. Assim, as evidências apontam a implicação da acumulação de capacidades para o consumo de energia.

Produtividade do trabalho. De forma análoga, a produtividade do trabalho teve sua performance otimizada a partir de 1997. Algumas atividades contribuíram para essa otimização, como as atividades de aprimoramento nos processos produtivos e a introdução de novas técnicas organizacionais (capacidades de Nível 4 em processo e organização da produção). Além disso, atividades como o treinamento para funcionários, minimização dos gargalos de produção, modificações no layout e a manutenção preventiva dos equipamentos igualmente influenciaram no desempenho da produtividade do trabalho. Com a implementação dessas atividades, a D'Itália obteve uma melhor organização da planta produtiva, o que possibilitou melhor utilização dos recursos físicos e humanos da empresa, permitindo a elevação da produtividade do trabalho de 2,66 produtos/hora homem no ano de 1996 para 3,91 produtos/hora homem em 1999.

Taxa de utilização da capacidade instalada. A D'Itália apresentou melhorias de performance neste indicador, tendo no período de 1998 e 1999 apresentado alongamentos na capacidade produtiva. Nesse momento, a 
D'Itália passou a executar atividades de organização da produção com base nos lotes diários, introdução de melhorias no layout dos equipamentos e a contratação de gerente e supervisor de produção, os quais passaram a coordenar a implantação dessas melhorias (atividades de Nível 4 em processo e organização da produção). No nível de equipamentos, no ano de 1995 a D'Itália passou a utilizar equipamentos automatizados, com a intensificação da manutenção preventiva desses equipamentos no ano de 1998 (capacidades de Nível 3 em equipamentos). Tais atividades foram fundamentais para a melhoria na performance da taxa de utilização da capacidade, tendo igualmente influência nos alongamentos de capacidade observados nos anos de 1998 e 1999 na D’Itália. Em resumo, pelo apresentado acima, a acumulação de capacidades tecnológicas, principalmente na função processo e organização da produção foi fator fundamental para que a D'Itália pudesse aprimorar sua performance técnica para os indicadores do Grupo 1.

No caso da Pozza, aumentos progressivos no consumo de energia foram observados a partir de 1980. A função processo e organização da produção apresenta implicações diretas no desempenho dos indicadores desse grupo. Nesse sentido, a Pozza apresentou trajetória crescente de acumulação das capacidades até 1980. Entretanto, a partir desse ano, observou-se uma paralisação na acumulação de capacidades, não tendo mais a Pozza apresentado atividades inovadoras a partir de então. Assim, ao contrário do observado na D'Itália, durante a trajetória técnicaa Pozza não apresentou a introdução de novas técnicas organizacionais, melhorias de layout, treinamento de funcionários, minimizações de gargalos e tampouco otimizações na planta produtiva. Essa ausência de acumulação de capacidades tecnológicas na Pozza sugere implicação para a performance do consumo de energia, o qual apresentou trajetória crescente. A performance deste indicador somente apresentou aprimoramentos após 1996, onde a Pozza iniciou a utilização de equipamentos automatizados, principalmente representados pelo centro de usinagem.

A paralisação na acumulação de capacidades tecnológicas na Pozza impactou igualmente no indicador produtividade do trabalho da Pozza. Com a ausência de atividades inovadoras, a Pozza apresentou reduções na produtividade, tendo este indicador apresentado uma taxa média anual de mudança de $-0,31 \%$. A taxa de utilização da capacidade, no período de 1963 a 2000, apresentou redução com taxa média anual de mudança de -1,37\%. Observam-se taxas de utilização de capacidade crescentes na Pozza até o ano de 1982. Até esse ano, a Pozza apresentava trajetória crescente de acumulação de capacidades tecnológicas nas três funções analisadas. Entretanto, com a paralisação na acumulação de capacidades por cerca de 30 anos, observou-se ao mesmo tempo a redução na performance da taxa de utilização da capacidade, as quais passaram a apresentar reduções sucessivas. As evidências sugerem, portanto, influência da acumulação de capacidades tecnológicas sobre a performance da taxa de utilização da capacidade na Pozza.

A D'Itália acumulou capacidades de maneira contínua para todas as três funções tecnológicas. Como visto acima, ela pôde executar uma série de atividades que auxiliaram na elevação dos padrões de performance técnica no início de sua operação. Assim, as evidências apresentadas sugerem que a acumulação de capacidades teve implicações positivas para a performance técnica medida por meio dos indicadores do Grupo 1. De outro lado, a ausência de atividades inovadoras na Pozza sugere implicações negativas para a performance técnica dos indicadores deste grupo. Em outras palavras, os casos estudados sugerem que, para os indicadores do Grupo 1, quanto maior o nível de acumulação de capacidades tecnológicas, melhor é evolução dos indicadores. Além disso, a ausência de acumulação de capacidades tecnológicas provoca efeitos negativos nos indicadores de performance técnica desses indicadores.

\subsubsection{Indicadores do Grupo 2}

Foram incluídos neste grupo os indicadores de performance técnica relacionados com a qualidade. Assim, foram descritos o índice de peças refugadas e a taxa de reclamação dos clientes.

Índices de peças refugadas. A D'Itália apresentou reduções sucessivas no índice de peças refugadas desde o início de suas atividades. Entretanto, a partir de 1996 esse indicador passou a apresentar melhoria em sua performance. Nesse mesmo período, a D'Itália passou a apresentar atividades de aprimoramento no processo produtivo, como a introdução dos lotes diários de produção. Nesse mesmo ano a D'Itália incorporou funções como a do gerente industrial, além dos supervisores, encarregados e coordenadores da produção. Tais atividades joga- 
ram papel fundamental para a organização da planta produtiva, ponto crítico para o desempenho do índice de peças refugadas. Aliadas a estas atividades, outras como a utilização de equipamentos automatizados no processo produtivo e as melhorias no layout de produção igualmente contribuíram para a redução do índice de peças refugadas. Assim, a utilização de novas técnicas organizacionais (capacidade de Nível 4 em processo e organização da produção), além da introdução dos $5 \mathrm{~S}$ e das reuniões diárias realizadas na empresa proporcionaram um melhor desempenho da planta produtiva da D'Itália. Com a acumulação dessas capacidades, o índice de peças refugadas na D'Itália, que apresentava 0,32\% em 1995 foi reduzido para 0,20\% em 1999. Assim, as evidências novamente apontam a implicação da acumulação de capacidades para o índice de peças refugadas.

Taxa de reclamação de clientes. Igualmente foi apresentada no Grupo 2. Pela evolução deste indicador, observa-se a redução do mesmo a partir de 1995. A partir deste ano, a D’Itália iniciou a elaboração dos móveis da linha reta. Com essa nova linha de produtos, observou-se a introdução de estudos para aprimoramento nos processos, onde foram introduzidos os lotes diários de produção. Novas técnicas organizacionais (capacidades de Nível 4 em processo e organização da produção) igualmente foram introduzidas, como a introdução do programa $5 \mathrm{~S}$. Além dessas atividades, outras como o acabamento nas bordas das peças e a conferência dos produtos elaborados contribuíram para a redução nas inconformidades na elaboração dos produtos da D'Itália. Com o desenvolvimento dessas atividades, a taxa de reclamação de clientes que era de 1,40\% em 1995 foi reduzida para 0,30\% em 2000. Assim, observa-se a influência da acumulação de capacidades na performance deste indicador.

Assim, pelo apresentado acima, as evidências sugerem que a acumulação de capacidades tecnológicas, principalmente na função processo e organização da produção, tenham contribuído para que a D'Itália pudesse aprimorar sua performance técnicapara os indicadores do Grupo 2.

Quanto à Pozza, aqui ocorre um fato análogo ao descrito para o Grupo 1 dos indicadores. Ou seja, a paralisação na acumulação das capacidades tecnológicas contribuiu negativamente para a performance dos indicadores de performance operacional. Nesse sentido, observa-se a redução apresentada pela Pozza no índice de peças refugadas até o ano de 1979. Ao contrário da situação verificada na D'Itália, por ter permanecido 30 anos sem apresentar atividades inovadoras, a Pozza não apresentou melhorias no layout, aprimoramento em processos, nem otimizações na organização da produção. Com a paralisação na acumulação de capacidades tecnológicas, o índice de peças refugadas já no ano de 1980 passou de 1,65\%, apresentando aumento em relação ao índice de $1,40 \%$ apresentado no ano anterior. Com a redução no volume de pedidos, o índice de peças refugadas apresentou redução no ano de 2000.

\subsubsection{Indicadores do Grupo 3}

O Grupo 3 apresenta os indicadores de performance técnica que estão associados basicamente à velocidade da empresa na elaboração e entrega dos produtos. Assim, o lead-time e o tempo de set-up foram incluídos neste grupo.

Lead time. No caso da D'Itália, após uma trajetória crescente neste indicador, observou-se o maior índice de lead-time no ano de 1994. Até esta data, a D'Itália executava atividades de rotina, tanto na função processo e organização da produção como na função equipamentos. A partir de 1995, atividades inovadoras foram observadas na D'Itália. Assim, novas técnicas organizacionais foram introduzidas (atividades de Nível 4 em processo e organização da produção), como os lotes diários de produção, as melhorias em layout e da atuação do gerente industrial. Além dessas atividades, destacam-se igualmente as melhorias ocorridas no nível de equipamentos, onde em 1995 foi iniciada a utilização de equipamentos automatizados para a fabricação dos produtos da D'Itália, os quais proporcionaram maior velocidade de produção à empresa. Atividades relacionadas à manutenção preventiva dos equipamentos igualmente foram observadas neste período (atividades de Nível 3 em equipamentos). A introdução dessas atividades implicaram em um incremento na performance do lead-time, o qual já no ano de 1995 apresentou redução significativa, passando de 18 para 7 dias.

Tempo de set-up. A D'Itália passou a apresentar condições de aprimoramento de performance neste indicador a partir de 1995. Algumas atividades contribuíram para esse aprimoramento, como a execução de melhorias no 
layout dos equipamentos, a atuação do gerente de produção a partir do ano de 1995, a organização da produção com base nos lotes diários de produção iniciada em 1996 e a implantação do programa 5 S (atividades de Nível 4 em processo e organização da produção). Além disso, a utilização de equipamentos automatizados e a organização da manutenção preventiva dos equipamentos (atividades de Nível 3 em equipamentos) igualmente apresentaram forte influência na redução do tempo de setup. Tais atividades influenciaram na performance do indicador tempo de setup que, no período de 1990 a 2000, apresentou uma taxa média anual de mudança de $10,62 \%$.

A Pozza também apresentou o maior índice de lead-time no ano de 1994. No período de 1963 a 1980, com a trajetória crescente de acumulação de capacidades tecnológicas, a Pozza apresentou uma linearidade por volta de oito dias de lead-time. Após esta data, ao mesmo tempo em que não foram observadas atividades inovadoras nas três funções tecnológicas analisadas, constata-se a elevação no lead-time da Pozza. No período de 1998 a 2000, observa-se uma pequena redução neste indicador, a qual sugere influência da utilização de equipamentos CNC na planta produtiva (atividade de Nível 4 em equipamentos). Apesar disso, em função do longo tempo decorrido sem a presença de atividades inovadoras, a Pozza apresentou elevação no lead-time com taxa média anual de mudança de 1,32\%. O desempenho do tempo de setup igualmente foi evidenciado neste grupo. Pelo apresentado, observa-se crescimento no tempo de setup na Pozza ao longo do tempo. Com a ausência de acumulação das capacidades tecnológicas após os anos 80, observa-se crescimento mais acelerado do tempo de setup que, no período de 1963 a 1990 apresentou elevação com taxa média anual de mudança de 2,24\%. Entretanto, no período de 1990 a 2000, este mesmo indicador apresentou elevação com taxa média anual de mudança de $7,67 \%$.

As evidências sugerem que, tanto para a D'Itália quanto para a Pozza, a acumulação de capacidades teve implicações positivas na performance técnica medida por meio dos indicadores do Grupo 3. Devido ao fato de a D'Itália ter acumulado mais rapidamente tais capacidades, esta foi capaz de manter níveis de performance técnicasuperiores aos da Pozza que, em função da paralisação na acumulação de capacidades, teve seus indicadores de performance prejudicados. Em outras palavras, os casos estudados sugerem que, para os indicadores do Grupo 3, quanto maior o nível de acumulação de capacidades tecnológicas, melhor será sua performance operacional.

\subsubsection{Indicadores do Grupo 4}

O Grupo 4 é constituído por indicadores mercadológicos, representados pelo market-share, exportação e o número de patentes. As atividades envolvidas nestes indicadores descrevem a performance da empresa no seu relacionamento com o mercado. No período de 1990 a 2000 a D'Itália apresentou uma significativa melhoria na performance técnicados indicadores mercadológicos, principalmente nos três últimos anos do período (1998 a 2000).

Market-share. Na D'Italia este indicador cresceu 50\% de 1999 a 2000. Nesse mesmo período, a D'Itália passou a executar atividades inovadoras em produtos, como o registro da patente da bancada para passar roupas, a utilização da engenharia reversa e do design como diferencial competitivo (capacidades de Nível 4 em produtos), além da diversificação do mix de produtos patenteados no ano de 2000 (capacidade de Nível 5 em produtos). Tais atividades foram fundamentais para a melhoria da performance do market-share da D'Itália, que no período de 1990 a 2000 evoluiu com uma taxa média anual de mudança de $31,10 \%$.

Exportação. De forma análoga, somente após o início de 1997 esse indicador passou a apresentar condições de aprimoramento de performance. Algumas atividades contribuíram para esse aprimoramento, como a existência de produtos patenteados pela D'Itália, o diferencial apresentado por estes produtos em função do design e a diversificação do mix (capacidades de Nível 4 e 5 em produtos). Com a introdução dessas atividades na D'Itália, observou-se o expressivo aumento na exportação que, no período de 1998 a 2000, aumentou com uma taxa média anual de mudança de $433,11 \%$.

No caso da Pozza, o desempenho do indicador market-share apresentou duas fases distintas. A primeira delas apresenta uma trajetória crescente para este indicador no período de 1963 a 1982, período este em que a Pozza 
apresentava uma trajetória crescente na acumulação de capacidades tecnológicas na função produtos, tendo alcançado Nível 4 nesta função. Entretanto, observa-se a ausência de acumulação de capacidades em produtos a partir de 1982. Essa ausência de acumulação em produtos sugere fortes implicações para a segunda fase deste indicador, o qual no período de 1983 a 2000 apresentou trajetória decrescente. Com referência à exportação, a Pozza apresentou índices com pequenas flutuações no período de 1976 a 2000. Essa trajetória sugere implicações com o fato de no período de 1963 a 1982 a Pozza ter concentrado suas vendas no mercado interno. Após este período, em decorrência de ter apresentado ausência de acumulação de capacidades em produtos, a Pozza não apresentava diferenciais competitivos no nível de produtos para desenvolver atividades de exportação. A ausência de atividades inovadoras após 1982 igualmente sugere implicações diretas no fato de a empresa não apresentar nenhuma patente industrial, tanto ao nível de produtos como no nível de processos.

As evidências apresentadas sugerem que, tanto para a D'Itália quanto para a Pozza, a acumulação de capacidades teve implicações positivas na performance dos indicadores mercadológicos. O fato de a D'Itália ter apresentado uma acumulação de capacidades de forma contínua e em níveis mais elevados foi capaz de ocasionar índices de performance técnica superiores aos da Pozza. Assim, as evidências sugerem que, para os indicadores do Grupo 4, a capacidade tecnológica acumulada de forma contínua nos indicadores desse grupo possibilita um melhor desempenho operacional. Ao comparar a evolução dos indicadores de performance técnica nas empresas estudadas, foram observadas diferenças em termos de taxa média anual de mudança dos indicadores. Assim, a evolução dos indicadores é apresentada na Tabela 4.

Patentes. De maneira análoga aos demais indicadores deste grupo, observa-se a influência da função produtos sobre o desempenho deste indicador, onde a D'Itália alcançou o Nível 5 nesta função. Como decorrência desse fato, a D'Itália apresentou o registro de duas patentes industriais. Uma destas patentes refere-se ao desenho industrial (DI) registrada no ano de 1998. O outro registro refere-se à bancada para passar roupas, que foi patenteada como modelo de utilidade (MU) em 1999. Assim, conforme apresentado nesta seção, depreende-se que a acumulação de capacidades tecnológica na função produtos foi fator fundamental para que a D'Itália pudesse aprimorar sua performance técnicapara os indicadores do Grupo 4.

Tabela 4. Resumo comparativo do aprimoramento de performance técnica nas empresas estudadas

\begin{tabular}{lcc}
\hline & $\begin{array}{c}\text { D'Itália } \\
\text { (Taxa média anual de } \\
\text { crescimento/ decréscimo } \\
\text { Indicadores examinados }\end{array}$ & $\begin{array}{c}\text { Pozza } \\
\text { (Taxa média anual de } \\
\text { crescimento/ decréscimo } \\
(\%)\end{array}$ \\
\hline 1. Consumo de energia & 13,55 & $-1,47$ \\
\hline 2. Produtividade do trabalho & 1,43 & 0,00 \\
\hline 3. Taxa de utilização da capacidade & 0,90 & $-5,53$ \\
\hline 4. Indice de peças refugadas & $-2,84$ & $-5,18$ \\
\hline 5. Taxa de reclamação de clientes & $-8,12$ & 4,14 \\
\hline 6. Lead time & 0,00 & 0,00 \\
\hline 7. Tempo de set-up & $-10,62$ & 7,67 \\
\hline 8. Market share & 31,10 & $-6,09$ \\
\hline 9. Exportação & 433,11 & 12,24 \\
\hline 10. Número de patentes & 2 & 0
\end{tabular}

Ao comparar as performances das empresas estudadas, observa-se que a D'Itália apresentou melhorias na maioria dos indicadores de performance operacional, com uma taxa média anual de mudança mais acelerada do que a Pozza. 


\subsection{Aprimoramento da performance econômico-financeira}

Esta seção examina as possíveis implicações da acumulação de capacidade tecnológica para o aprimoramento da performance econômico-financeira na Pozza e na D'Itália, no período de 1976 a 2000. Os indicadores que evidenciam a performance econômico-financeira são apresentados na Tabela 5.

Tabela 5. Indicadores de performance econômico-financeira

\begin{tabular}{ll}
\hline Indicadores examinados & Unidade \\
\hline Giro de estoques & Número de vezes por ano \\
\hline Margem de lucro operacional & $(\%)$ \\
\hline ROI (Return on Investment) & $(\%)$ \\
\hline Margem líquida & $(\%)$ \\
\hline Endividamento geral & $(\%)$ \\
\hline Nível de desconto de títulos & $(\%)$ \\
\hline
\end{tabular}

Giro de estoques. Conforme análise da performance das empresas, no período de 1990 a 2000 a D'Itália apresentou trajetória crescente no giro dos estoques. Entretanto, a partir de 1995 observa-se uma mudança mais acelerada neste indicador. $\mathrm{O}$ desempenho deste indicador é determinado pelo custo dos produtos vendidos e pelo estoque médio da empresa. Os indicadores de performance técnica bordados neste estudo influenciam parcialmente na performance do giro dos estoques. A performance técnica apresenta influência direta sobre o giro dos estoques da empresa. Entretanto, essa influência parece ter sido relativa uma vez que é parcial em virtude de a performance técnica não possuir influência sobre o nível dos estoques da empresa. Assim, todos os fatores relacionados com o custo de produção da empresa influenciam na performance do giro dos estoques.

Assim, observa-se que a partir de 1995 a D'Itália apresentou reduções progressivas no índice de peças refugadas. A taxa de reclamação de clientes, com a redução evidenciada a partir de 1995, igualmente trouxe reflexos para o giro dos estoques, em virtude de ter apresentado uma taxa média anual de mudança de $-22,64 \%$. Da mesma maneira, o tempo de setup apresentou redução a partir de 1995, o qual implicou em aprimoramento do giro dos estoques da D'Itália. Com relação a Pozza, observa-se a paralisação na acumulação de capacidades por um longo período, o que trouxe implicações para os indicadores de performance operacional. Com a redução verificada na Pozza nestes indicadores, observa-se a influência negativa destes sobre o custo dos produtos vendidos, ocasionando redução no giro dos estoques da Pozza até o início dos anos 1990. Assim, observa-se a implicação parcial da performance técnica sobre o desempenho do giro dos estoques nas empresas estudadas.

Margem de lucro operacional. Observam-se trajetórias diferenciadas para a D'Itália e para a Pozza referente a esse indicador. O desempenho deste indicador é determinado pelo lucro técnicae pelas vendas líquidas da empresa. Dessa forma, os indicadores de performance que influenciam no lucro operacional possuem relacionamento direto com o indicador margem de lucro operacional.

A D'Itália apresentou em 1996 um aumento significativo neste indicador. Ao mesmo tempo, observa-se que a partir de 1995 a D'Itália apresentou reduções progressivas no índice de peças refugadas. A taxa de reclamação de clientes, com a redução evidenciada a partir de 1995, a qual apresentou redução no período de 1995 a 2000 com uma taxa média anual de mudança de $-22,64 \%$, igualmente influenciou a performance da margem de lucro operacional. Da mesma maneira, o tempo de setup apresentou redução a partir de 1995, onde passou de 980 minutos/ano em 1994 para 260 minutos/ano em 1995. Dessa maneira, a introdução dessas atividades na D'Itália influenciaram na performance do indicador margem de lucro operacional, que passou de $-40 \%$ em 1995 para 6\% em 1996. Observa-se ainda a influência do indicador exportação sobre a margem de lucro técnicada D'Itália, uma vez que o aumento da exportação no ano de 2000 ocasionou uma correspondente elevação na margem de lucro técnicano mesmo período.

De outro lado, a Pozza não conseguiu melhorar esse indicador, apresentando queda progressiva no mesmo desde meados dos anos 1980. Associado à redução da margem de lucro técnicana Pozza, observa-se a paralisação nas atividades de acumulação de capacidades tecnológicas igualmente a partir dos anos 1980. A partir dessa 
época, não foram localizadas atividades inovadoras ao nível de processo e organização da produção e produtos na Pozza. Com isso, a margem de lucro técnicada Pozza passou de 56\% em 1988 para $-29 \%$ em 2000, tendo sido reduzida no período de 1976 a 2000 com uma taxa média anual de mudança de $-202,80 \%$. Dessa forma, constata-se a implicação da performance técnicasobre a margem de lucro técnica nas empresas estudadas.

Retorno do investimento. A D'Itália e a Pozza novamente apresentaram trajetórias distintas referente a esse indicador. Nesse sentido, todos os indicadores de performance técnica que estão relacionados com o lucro líquido ou com a formação do ativo total possuem influência na performance do ROI. Assim, os indicadores de performance técnica mencionados acima para a margem de lucro operacional igualmente influenciaram no desempenho do ROI na D'Itália. Dessa maneira, a D'Itália apresentou taxas decrescentes até o ano de 1995, quando apresentou um índice retorno do investimento de $-26 \%$. Após a introdução de atividades relacionadas à capacidades tecnológicas que influenciaram na performance operacional, a D’Itália apresentou já no ano de 1996 um ROI de $13 \%$, tendo este sido elevado nos anos subseqüentes.

Novamente observa-se a influência do indicador exportação sobre a performance do ROI na D'Itália, pois a elevação da exportação observada no ano de 2000 influenciou na performance do ROI no mesmo ano. De outro lado, a Pozza apresentou índices negativos nesses últimos anos referente ao retorno do investimento. Em decorrência da reestruturação organizacional implantada, onde unidades fabris foram vendidas e produtos foram tirados da linha de fabricação, a Pozza veio perdendo sua fatia de mercado, acarretando faturamentos e margens de lucro cada vez menores. Paralelamente a essa reestruturação, não foram constatadas implementações de atividades inovadoras nas três funções analisadas, tendo a Pozza limitado a realizar tarefas que já apresentava há bastante tempo. Assim, o ROI da Pozza que era $6 \%$ em 1980, foi reduzido para $-11 \%$ em 2000. Com isso, fica evidenciada a implicação da performance técnica sobre o ROI nas empresas estudadas.

Margem líquida. De maneira análoga aos indicadores anteriormente apresentados, a D'Itália e a Pozza apresentaram trajetórias diferenciadas para este indicador. Este é determinado através da relação entre o lucro líquido e a receita líquida da empresa. Em função de este indicador estar relacionado com o lucro líquido, os indicadores de performance técnica que influenciaram no desempenho da margem líquida são os mesmos apresentados para a margem de lucro técnicae ao ROI. Novamente observa-se a influência do indicador exportação, além dos demais indicadores mercadológicos, na performance da margem líquida. Assim, em decorrência da elevação do market-share e das exportações, respaldados pelos produtos patenteados da empresa, a D'Itália apresentou aumento na margem líquida, a qual passou de 2,85\% em 1997 para 15,82\% em 2000. Por sua vez, entre os anos de 1976 a 2000, a Pozza apresentou períodos alternados entre margens positivas com margens negativas referente a esse indicador. Como a margem líquida utiliza como base de análise o lucro líquido apresentado, todos os fatores que se relacionam o lucro líquido possuem relação direta com a margem líquida. Dessa maneira, como a ausência de acumulação de capacidades tecnológicas pela Pozza implicou em redução nos indicadores de performance operacional, este fato influenciou para que a margem líquida da Pozza foi reduzida no período de 1976 a 2000 com taxa média anual de mudança de $-202,60 \%$. Assim, fica evidenciada a implicação da performance técnicasobre a margem líquida nas empresas estudadas.

Endividamento geral. Este indicador é determinado pelos valores integrantes do ativo total e do passivo das empresas (bens, direitos e obrigações). Por sua vez, os indicadores de performance técnica analisados nesse trabalho possuem influência direta sobre receitas e despesas da empresa. Assim, observa-se que os indicadores de performance técnica examinados aqui não possuem relação direta com a performance do endividamento geral. Entretanto, os mesmos influenciam indiretamente esse indicador, uma vez que as receitas e despesas terão reflexos no ativo (p. ex. aumento de numerário) e no passivo (p. ex. redução nas contas a pagar) destas empresas.

Foi apresentado ainda o indicador nível de desconto de títulos como indicador de performance econômicofinanceira da empresa. Este indicador é determinado pelo volume de desconto de títulos e pelo volume de duplicatas a receber da empresa. A D'Itália apresentou incremento no market-share, na exportação e no número de patentes a partir de 1998. Esse fato sugere implicações indiretas da performance técnicacom o nível de desconto de títulos, uma vez que a elevação nesses indicadores sugere uma elevação na receita da empresa, o que acarretará um aumento nas duplicatas a receber. Essa elevação sugere implicações com o desempenho do nível 
de desconto de títulos da D’Itália, o qual apresentou índice de 23\% em 1997 e foi zerado nos anos subseqüentes.

Contudo, a implicação da performance técnica sobre o nível de desconto de títulos é indireta, em virtude de o volume de desconto de títulos ser definido através de políticas da empresa, apesar de também ser indiretamente influenciado pelos indicadores operacionais. Da mesma forma dos itens anteriores, a Pozza não conseguiu eliminar a atividade de desconto de títulos, influenciada pela paralisação da acumulação de capacidades tecnológicas. Assim, com a queda de performance dos indicadores operacionais, a empresa ainda apresentou índices de desconto de títulos em 2000. Observa-se a redução progressiva deste indicador nos últimos três anos. Contudo, essa redução sugere implicações com o fato de a empresa estar sob o benefício da concordata preventiva. Assim, observa-se a implicação parcial da performance técnica sobre o desempenho do nível de desconto de títulos nas empresas estudadas.

Ao comparar o aprimoramento da performance econômico-financeira das empresas estudadas, observam-se diferenças em termos de taxa média anual de mudança dos indicadores, conforme apresentado na Tabela 6. Entretanto, destaca-se que a D'Itália apresentou uma taxa de mudança mais acelerada do que a Pozza, fato este que sugere implicações diretas com o aprimoramento de seus indicadores.

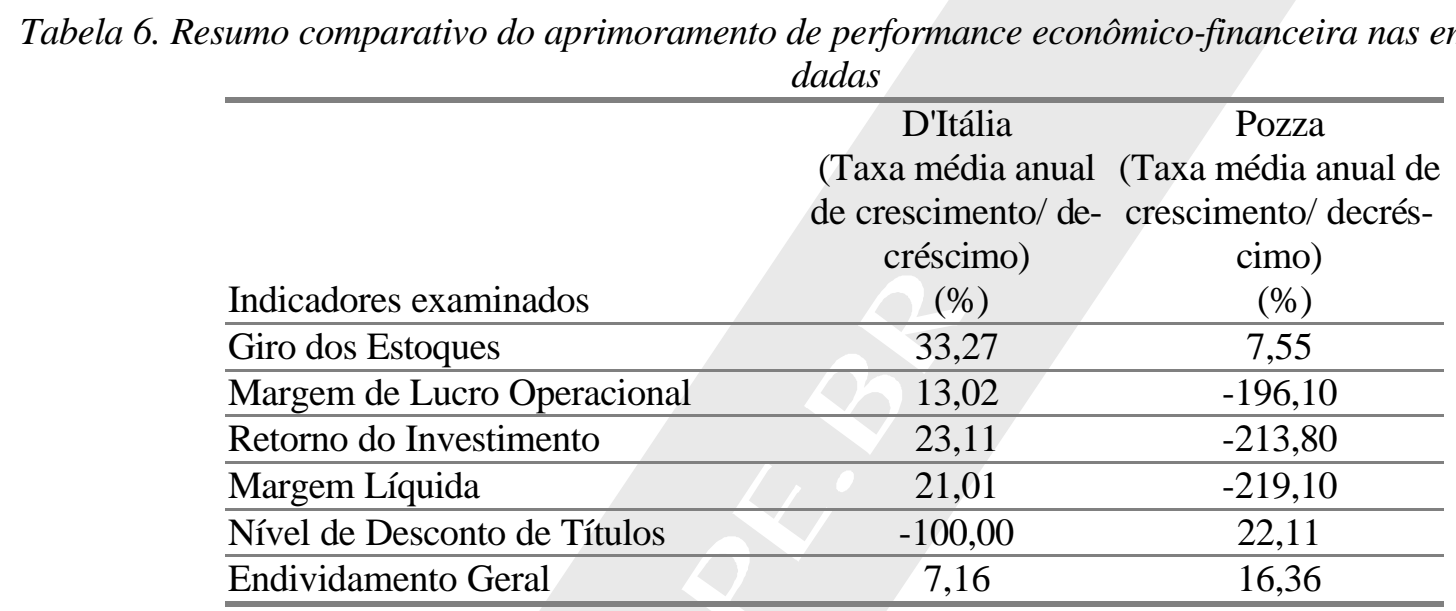

Fonte: Elaboração do próprio autor.

As evidências acima sugerem que, tanto para a D'Itália como para a Pozza, a performance técnicateve implicações diretas ou indiretas nos indicadores de performance econômico-financeira dessas empresas. Em outras palavras, quanto maior o nível de performance operacional, melhor será a performance econômico-financeira da empresa. Assim, observa-se a existência de implicações práticas da acumulação de capacidades tecnológicas para o aperfeiçoamento da performance corporativa.

\section{Conclusões e implicações para gestão}

Este trabalho examinou as implicações da acumulação de capacidades tecnológicas para o aprimoramento de performance corporativa na D'Itália (1990 a 2000) e na Pozza (1963 a 2000). O estudo fez uso de uma métrica sistemática, compreensiva e calibrada para a indústria moveleira para examinar a acumulação de capacidades para quatro tipos de atividade: (i) processo e organização da produção; (ii) produtos; e (iii) equipamentos. $\mathrm{O}$ artigo fez uso de um amplo número de indicadores de performance técnico-operacional, em nível das empresas estudadas. Mais especificamente, em relação às empresas estudas concluímos que:

(i) Em termos de acumulação de capacidades tecnológicas. No início de suas operações, tanto a D'Itália quanto a Pozza careciam até mesmo de capacidades básicas para operarem suas plantas produtivas. No entanto, logo 
após a ativação de suas plantas, essas empresas engajaram-se na acumulação de capacidades tecnológicas. Com o início das atividades em 1990, a D’Itália acumulou suas capacidades tecnológicas nas três funções de maneira semelhante, apresentando uma trajetória evolutiva crescente ao longo do tempo. Em 1995, a empresa iniciou a produção de móveis da linha reta, juntamente com a introdução de melhorias relacionadas a processo e organização da produção, produtos e equipamentos. Com a melhoria contínua aplicada nos processos internos, a D'Itália passou a apresentar equipamentos automatizados, produtos e processos patenteados e a utilização do design como diferencial competitivo, entre outras. Nessas condições, a D’Itália passou a apresentar uma velocidade mais acentuada no processo de acumulação de capacidades para todas as funções tecnológicas estudadas, alcançando o Nível 5 na função produtos, Nível 4 na função processo e organização da produção e Nível 3 na função equipamentos.

Por outro lado, verifica-se que a Pozza iniciou suas atividades em 1963. Em decorrência de sua trajetória crescente de acumulação de capacidades tecnológicas, a Pozza chegou a ser uma das maiores empresas de móveis do Brasil nos anos 1980. Entretanto, ao longo de sua existência a Pozza não avançou além do Nível 4 de capacidade para atividades de produtos e de equipamentos, e do Nível 3 para atividades de processo e organização da produção.

(ii) Diferenças inter-empresariais em termos de performance técnico-econômica. As evidências apresentadas sugerem que a acumulação de capacidades tecnológicas em processo e organização da produção, produtos e equipamentos são fundamentais para o desenvolvimento da performance técnica das empresas do setor moveleiro. Nesse sentido, a acumulação dessas capacidades permitiu à D'Itália introduzir novas técnicas em sua planta fabril, as quais proporcionaram um rápido crescimento da empresa, além de sua estruturação para atuar no mercado moveleiro. Assim, verifica-se que em virtude de ter acumulado suas capacidades tecnológicas de maneira compreensiva, ou seja, com velocidade semelhante para as três funções tecnológicas analisadas, a D'Itália apresentou uma melhor performance operacional. Fato análogo ocorreu com a Pozza. No período em que apresentava acumulação de capacidades tecnológicas, a Pozza aprimorava seus processos, produtos e equipamentos, dando suporte ao crescimento verificado na empresa. Entretanto, após a paralisação na acumulação das capacidades, a Pozza reestruturou suas unidades produtivas, reduzindo sua participação no mercado.

Da mesma maneira, constatou-se que a performance econômico-financeira das empresas estudadas, por serem uma decorrência da performance operacional, igualmente foi influenciada pela acumulação de capacidades tecnológicas. Assim, pelo exposto acima, as evidências sugerem que a acumulação de capacidades em processo e organização da produção, produtos e equipamentos tiveram implicações significativas na melhoria da performance econômico-financeira das empresas do setor moveleiro estudadas.

A melhoria do desempenho operacional é questão da maior importância para as empresas em geral, sobretudo as empresas em industrialização, que começam com níveis de desempenho muito abaixo dos padrões mundiais. Para alcançar esses padrões, elas têm que melhorar seu desempenho operacional mais rapidamente do que as empresas que operaram na fronteira tecnológica. Sua competitividade no âmbito mundial depende da rapidez com que conseguem acumular competência tecnológica (Bell et al, 1982, Bell at al., 1995). Somente alguns estuds, investigaram sistematicamente a melhoria do desempenho operacional associada à acumulação de competência tecnológica (por exemplo, Dahlman \& Fonseca, 1978; Katz et al., 1978; Bell et al., 1982; Mlawa, 1983; Tremblay, 1994; Figueiredo, 2001; Castro \& Figueiredo, 2005).

As evidências neste estudo sugerem o relevante papel da acumulação de capacidades no aprimoramento da performance técnico-econômica nas empresas estudadas. Nesse sentido, o estudo realizado está alinhado a trabalhos anteriores sobre a importância estratégica da acumulação para empresas em industrialização (semelhantes às estudadas neste trabalho) como, por exemplo, Bell \& Pavitt (1995), Tremblay (1994), Lall (1987) e Teece et al. (1990). Em suma, as evidencias dessas suas empresas moveleira indicam que:

- Quanto maior o nível de acumulação de capacidades tecnológicas das empresas, melhor foi o seu desempenho em termos de performance operacional. Essa conclusão está de acordo com estudos anteriormente realizados (Dosi, 1988; Bell \& Pavitt, 1995; Tremblay, 1994; Teece et al., 1990). 
- Diferenças nas trajetórias de acumulação de capacidades tecnológicas tiveram implicações significativas na diferença de performance técnica entre as empresas estudadas. Este ponto ratifica estudos anteriores, como, por exemplo, Penrose (1959), Hollander (1965), Dosi (1988), e Teece et al. (1990).

- Os indicadores de performance técnica influenciaram direta ou indiretamente a performance dos indicadores econômico-financeiros. Assim, a acumulação de capacidades tecnológicas influenciou na performance corporativa das empresas estudadas. Essa conclusão está de acordo com estudos anteriormente realizados, como Penrose (1959), Mlawa (1983), Bell et al., (1982), Katz (1987), Nelson (1991), Pisano (1997) e Figueiredo (2001), Castro \& Figueiredo (2005).

A métrica para usada neste artigo para exame de capacidades tecnológicas pode auxiliar na gestão empresarial através da identificação de oportunidades de melhoria de performance técnico-econômica pela acumulação tecnológica. Esta ferramenta analítica pode auxiliar também na orientação de estudos de políticas governamentais para desenvolvimento tecnológico, identificando oportunidades de melhoria na capacitação tecnológica de setores industriais estratégicos.

Através do exame da relação entre processos de aprendizagem, acumulação de capacidades tecnológicas e aprimoramento de performance técnico econômica na aciaria da CSN, este estudo avança em relação aos estudos anteriores (por exemplo, Tacla \& Figueiredo, 2003; Castro \& Figueiredo, 2005) sobre essas questões ao examinar diferenças entre duas empresas do mesmo setor industrial em termos de acumulação de capacidade tecnológica e suas implicações para performance técnico-econômica.. Ao fazer isso mostramos aqui a viabilidade de aplicação dos modelos de análise de capacidades tecnológicas em nível de empresas. Além disso, este estudo contribui para abrir caminho para futuras comparações entre unidades operacionais específicas tanto em nível da mesma empresa como em nível inter-empresarial. Isso possibilitaria um entendimento ainda mais detalhado sobre as implicações práticas dos processos de aprendizagem para o aprimoramento da performance de empresas de setores estratégicos da indústria no Brasil. 


\section{Referências bibliográficas}

ARIFFIN, N. The internationalisation of innovative capabilities: the Malaysian electronics industry. 2000. Thesis (D. Phil.) -- SPRU, University of Sussex, Brighton, 2000.

BELL, M. \& PAVITT, K. Technological accumulation and industrial growth: contrasts between developed and developing countries. Industrial and Corporate Change. London, v. 2, n. 2, 1993, pp. 157-211. Bank $\overline{1} \overline{1} 9 \overline{9}$

The development of technological capabilities. Technology and International competitiveness. Washington: The World

BELL, M., SCOTT-KEMMIS. D. \& SATYARAKWIT, W. 'Limited learning in infant industry: a case study', in F. Stewart and J. James (eds), The Economics of New Technology in Developing Countries. Frances Pinter: London, 1982

BELL, M; HOBDAY, M., ABDULLAH S., ARIFFIN N. \& MALIK J. 'Aiming for 2020: a Demand-

Driven Perspective on Industrial Technology in Malaysia.' Final Report for the World Bank and Ministry of Science, Technology and the Environment, Malaysia, SPRU, University of Sussex, 1995.

; WESTPHAL, L. Technological effort in industrial development: an interpretative survey of recent research. In: STEWART, F.; JAM ES, J. (Eds.). The economics of new technology in developing countries. London: Frances Pinter, 1982. p. 105-137.

CASTRO, E. \& FIGUEIREDO, P.N. "Aprendizagem tecnológica compensa? Implicações da acumulação de competências para o aprimoramento de performance técnica em uma aciaria no Brasil (1997-2001)", Revista de Administração Contemporânea, Vol. 9, 1a. Edição Especial, 2005, pp. 109- 133.

DAHLM AN, C. \& FONSECA F.V. 'From Technological Dependence to Technological Development: The Case of the USIM INAS Steel Plant in Brazil,' Working Paper, no. 21, IBD/ECLA Research Programme, 1978.

DOSI, G. 'The Microeconomic Sources and Effects of Innovation. An Assessment of Some Recent Findings', DRC Discussion Paper, n. 33. SPRU, University of Sussex, 1985.

; ORSENIGO, L. Coordination and Transformation: an Overview of Structures, Behaviour and Change in Evolutionary Environments, IN : G DOSI et al., Technical Change and Economic Theory, London: Printer, 1988.

DUTRENIT, G. Learning and Knowledge Management in the Firm: From Knowledge Accumulation to Strategic Capabilities (New Horizons in the Economics of Innovation); Hardcover, 2000.

FIGUEIREDO, P. N. Technological learning and competitive performance. Cheltenham, UK; Northampton, MA, USA: Edward Elgar Publishing, 2001.

. Does technological learning pay off? Implications for inter-firm differences in operational performance improvement. Research Policy (Elsevier Science), v.31, № 1, 2002, pp. 73-94

. Aprendizagem tecnológica e performance competitiva. Rio de Janeiro: FGV, 2003.

HOBDAY, M., Innovation in East Asia: the challenge to Japan. Aldershot: Edward Elgar, 1995.

HOLLANDER, S., The sources of increased efficiency: a study of Du Pont rayon plants. Cambridge, MA: MIT Press, 1965.

KATZ, J. 'Domestic Technology Generation in LDCs: a Review of Research Findings', IN: Katz J. (ed.), Technology Generation in Latin American Manufacturing Industries, New York: St Martin's Press, 1987.

KATZ, J; GUTKOWSKI M.; RODRIGUES M. \& GOITY G. 'Productivity, Technology, and Domestic Efforts in Research and Development', Working Paper n. 14, Buenos Aires, ECLA/IDB/IDRC/UNDP Research Programme on Scientific and Technological Development in Latin America, 1978.

KIM, L. The Dynamics of Samsung's Technological Learning in Semiconductors, California Management Review, v.39, nㅇ 3, 1997a, pp. 86100. Imitation to Innovation: The Dynamics of Korea's Technological Learning, Boston, MA: Harvard Business School Press, 1997b.

LALL, S. Technological learning in the Third World: some implications of technology exports. In: STEWART, F.; JAMES, J. (Eds.). The economics of new technology in developing countries. London: Frances Pinter, 1982.

Learning to industrialise: the acquisition of technological capability by India. London: Macmillan, 1987.

. Technological Capabilities and industrialization. World Development. London, v. 20, n. 2, pp. 165-186, 1992.

MLAWA, $H$. The acquisition of technology, technological capability and technical change: A study of the textile industry in Tanzania. D.Phil. Thesis, SPRU, University of Sussex, 1983.

NELSON, R. \& WINTER S. An Evolutionary Theory of Economic Change, Cambridge, MA: Harvard University Press, 1982. 
PATTON, M. Q. Qualitative Evaluation and Research Methods, 2nd edn, Newbury Park, California: Sage, 1990.

PAVITT, K., 'Key characteristics of the large innovating firm', British Journal of Management, 2, 1991, pp. 41-50.

PENROSE, E. T. The theory of the growth of the firm. Oxford: Basil Blackwell, 1959.

PISANO, G. The Development Factory: Unlocking the Potential of Process Innovation, Boston, MA: Harvard Business School Press, 1997.

RUMELT, R. P., Strategy, structure and economic performance. Cambridge, MA: Harvard University Press, 1974.

TACLA, C. L. \& FIGUEIREDO, P. N. Processos de aprendizagem e acumulação de capacidades tecnológicas: evidências de uma empresa de bens de capital no Brasil. Revista de Administração Contemporânea, v. 7, n. 3, pp. 101-126, 2003.

TEECE, D. \& PISANO G. The Dynamic Capabilities of Firms: an Introduction, Industrial and Corporate Change, v. 3, n. 3, 1994, pp. 537- 56.

TEECE, D.; PISANO G. \& SHUEN A. Firm Capabilities, Resources, and the Concept of Strategy: Four Paradigms of Strategic Management, CCC Working Paper, No.94-9, University of California at Berkeley. 1990.

TREM BLAY, P. Comparative analysis of technological capability and productivity growth in the pulp and paper industry in industrialised and industrialising countries. 1994. Thesis (D. Phil.) -- SPRU, University of Sussex, Brighton, 1994. 